\title{
Relationship of the Severity of Citrus Greasy Spot, Caused by Mycosphaerella citri, to Ascospore Dose, Epiphytic Growth, Leaf Age, and Fungicide Timing
}

\author{
S. N. Mondal and L. W. Timmer, University of Florida, IFAS, Citrus Research and Education Center, Department \\ of Plant Pathology, Lake Alfred 33850
}

\begin{abstract}
Mondal, S. N., and Timmer, L. W. 2006. Relationship of the severity of citrus greasy spot, caused by Mycosphaerella citri, to ascospore dose, epiphytic growth, leaf age, and fungicide timing. Plant Dis. 90:220-224.

Greasy spot, caused by Mycosphaerella citri, produces leaf and fruit lesions and defoliates trees, resulting in reduced yields and fruit size. Techniques now available allow production of large numbers of ascospores and the quantification of epiphytic growth. The effects of ascospore dose, leaf age, and the timing of fenbuconazole sprays on epiphytic growth and disease severity was determined primarily on rough lemon seedlings in the greenhouse. Inoculation of leaves with $10^{4}$ ascospores $/ \mathrm{ml}$ resulted in rapid development of epiphytic growth and symptoms. At lower doses, epiphytic growth and symptoms developed more slowly and were less severe. There was a linear relationship between $\log _{10}$ of the ascospore dose and ratings of epiphytic growth and symptoms, and a linear relationship between the amount of epiphytic growth and symptom severity in greenhouse tests. On grapefruit trees treated with different fungicides in six field experiments, there also was a significant linear relationship between epiphytic growth of $M$. citri measured in August and symptom severity rated in February to March of the following year, but coefficients of determination were much lower than in greenhouse experiments. Leaf age from 10 to 60 days did not affect susceptibility of leaves to $M$. citri. Fenbuconazole applied up to 50 days prior to inoculation still reduced epiphytic growth and greasy spot severity under greenhouse conditions, but the postinoculation treatments were effective for only 30 days.
\end{abstract}

Greasy spot, caused by Mycosphaerella citri Whiteside, is widespread in the Caribbean area, including Florida, eastern Mexico, Central America, northern South America, and the islands of the Caribbean (14). Related diseases caused by other Mycosphaerella spp. occur elsewhere in the world (14). M. citri produces slowdeveloping, oily lesions that cause premature defoliation and, subsequently, reduced yield and fruit size. Fruit infections produce dark specks on the fruit that coalesce to form greasy spot rind blotch. Greasy spot is most serious on lemons and grapefruit, but affects most citrus and its relatives.

The basic biology and disease cycle of $M$. citri have been well-studied (79,11,18,19,21,22). Pseudothecia of $M$. citri are formed in decomposing leaf litter following repeated wetting and drying of

Corresponding author: L. W. Timmer

E-mail: 1wt@crec.ifas.ufl.edu

This research was supported in part by the Florida Agricultural Experiment Station and approved for publication as Journal Series No. R-10530. This research was partially funded by the Florida Citrus Production Research Advisory Committee Project No. 043-07P.

Accepted for publication 23 September 2005.

DOI: 10.1094/PD-90-0220

(C) 2006 The American Phytopathological Society leaves in the spring. Wetting of leaves with mature pseudothecia triggers the release of ascospores. Ascospores deposited on the underside of the leaves germinate and the mycelium grows epiphytically during the summer rainy season in Florida. Hyphae penetrate through stomata and develop slowly in the mesophyll, and symptom development frequently requires 3 to 6 months, depending on the species of citrus and the conditions. In Florida, symptoms begin to develop in November to December and leaf drop usually occurs in February to March, prior to emergence of the spring flush of growth (14).

Over the last several years, we have investigated pseudothecial production, ascospore release, and the mating system in $M$. citri, as well as the mycelial growth of the pathogen on leaves and fruit $(7-9,11)$. However, there are many aspects of the biology of this pathogen that have not been studied because techniques have not been available for certain types of investigation. Virtually all inoculations to date have been conducted using macerated mycelium rather than ascospores $(18,19,21)$ because ascospores were difficult to produce in large numbers. The infection process includes an epiphytic growth stage, but means have not been available to routinely quantify the amounts of mycelial growth on the plant surface. The relationship between inoculum dose, epiphytic growth, and disease incidence or severity has not been investigated. It is presumed that leaves of all ages can be infected (14) but that has never been verified experimentally.

Timing of fungicide applications on spring growth flushes in Florida is flexible because epiphytic growth does not begin until the summer rainy season $(11,17)$. However, summer growth flushes must be protected promptly because conditions are highly favorable for infection at that time. Under field conditions, tissues are exposed to variable amounts of inoculum over a long period of time and environmental conditions vary during the infection periods. There is no information on the longevity of fungicide deposits when materials are applied preventively or on the ability of products to eliminate epiphytic growth from the leaf surface. Whiteside (24) felt that fungicides could be applied up to several weeks after spore deposition and still control disease. Thus, he recommended delaying applications well into the summer.

Techniques have now been developed to allow efficient production of pseudothecia (9) as well as the release and collection of large numbers of ascospores (7). Means also have been developed to rapidly assess and quantify epiphytic growth $(11,13)$. The purpose of this study was to determine the relationship between ascospore dose, epiphytic growth, and disease severity in the laboratory and the field. The effect of leaf age on susceptibility to greasy spot and the effect of timing of fungicide applications on development of epiphytic growth and disease symptoms under greenhouse conditions also were investigated.

\section{MATERIALS AND METHODS}

Plant material. Rough lemon (Citrus jambhiri Lush) was used for all experiments because it is very susceptible to greasy spot. Seedlings were grown in the greenhouse as a single stem in 2.5-liter plastic pots in a soilless potting mix. Following inoculation, seedlings were topped at about $0.7 \mathrm{~m}$ and all of the subsequent new growth was removed to maintain a single stem bearing only the inoculated leaves.

Inoculations. Naturally infected leaves of grapefruit (C. paradisi Macf.) with greasy spot symptoms were collected in the field and placed in mesh bags on the grove floor under the trees. Leaves were allowed to decompose naturally until ma- 
ture pseudothecia were formed. About 50 decomposing leaves were selected, moistened, and placed in a wooden wind tunnel apparatus first described by Whiteside (20) and modified by Mondal and Timmer (9) to collect the ascospores released. A tube was attached to the end of the tunnel which was connected to a test tube with $10 \mathrm{ml}$ of a $10 \%$ glycerol solution. Ascospores were collected for several hours by bubbling air through the glycerol solution. Generally, about $10^{4}$ ascospores $/ \mathrm{ml}$ were recovered by this procedure.

Rough lemon seedlings were inoculated with a suspension of ascospores by spraying to run-off with a hand-pump sprayer. Ascospore concentration was $10^{4}$ ascospores $/ \mathrm{ml}$ unless otherwise indicated. Inoculated plants were placed in a mist bed and maintained constantly wet for $16 \mathrm{~h}$. Plants were transferred to the greenhouse where temperatures varied from 15 to $35^{\circ} \mathrm{C}$ and relative humidity ranged from 50 to near $100 \%$, but plants were not exposed to free moisture.

Evaluations. Discs (7 $\mathrm{mm}$ in diameter) were cut from leaves of test plants using a cork borer in order to evaluate epiphytic growth. About 30 discs, collected from three leaves of each replicate seedling, were evaluated at each sample time. Leaf discs were cleared in $95 \%$ ethanol and lactophenol (2:1, vol/vol) for 6 days following the method of Skaria and Zhang (10). Cleared discs were stained with $0.1 \%$ trypan blue in $50 \%$ glycerol for $24 \mathrm{~h}$, then rinsed two to three times with water and stored in $50 \%$ glycerol until observed. The abaxial surfaces of discs were examined at $\times 200$ under a compound microscope and the density of the epiphytic growth rated on a scale where $0=$ no visible mycelium; $1=$ scattered hyphae, $<10 \%$ coverage; $2=$ 10 to $25 \%$ coverage; $3=26$ to $75 \%$ coverage; $4=76$ to $100 \%$ coverage; and $5=$ $100 \%$ coverage, with very dense growth covering the entire surface (10).

Greasy spot severity was rated on a scale where $0=$ no symptoms, $1=1$ to $5 \%$ of the surface areas with lesions, $2=6$ to $10 \%, 3=11$ to $15 \%, 4=16$ to $20 \%$, and 5 $=$ more than $20 \%$ or leaf abscessed. Only the actual lesion areas were considered in the ratings and the surrounding chlorotic areas were disregarded $(8,16)$.

Experimental procedures. Ascospore dose. Three experiments were conducted to determine the effect of ascospore dose on the development of epiphytic growth and greasy spot severity in March, April, and May 2003. In each, 10 replicate plants were inoculated with ascospores at concentrations of $10^{1}, 10^{2}, 10^{3}$, and $10^{4}$ ascospores $/ \mathrm{ml}$. Three replicate plants were designated for destructive sampling for epiphytic growth and all leaves on the remaining seven plants were rated for symptom severity. Samples for epiphytic growth were collected as described above and processed biweekly for the first 90 days. Symptom severity was rated monthly from 60 to 180 days after inoculation. The outcome of the three experiments was similar and the development of epiphytic growth and symptom development was related to time across all experiments and standard errors were calculated for each mean.

Epiphytic growth. The relationship of epiphytic growth to symptom severity was assessed in the experiment on ascospore dose. The amount of epiphytic growth on the plants in all three experiments inoculated with each ascospore dose at 75 days was calculated. Similarly, the greasy spot severity in each treatment assessed at 150 days was averaged for each treatment.
Regression analysis was used to relate the two factors using data from all three experiments.

The relationship between epiphytic growth and greasy spot severity was determined in fungicide evaluations carried out in grapefruit groves near Lake Alfred, FL. Fungicides were evaluated in 2002 03 in four trials and in 2003-04 in two trials. Fungicides were applied with a handgun sprayer to five replicate two-tree plots arranged in a randomized complete block design. Details of the trials and fungicide performance for the 2002-03 trials and the 2003-04 trials have been published in Fungicide and Nematicide Tests (2-6).
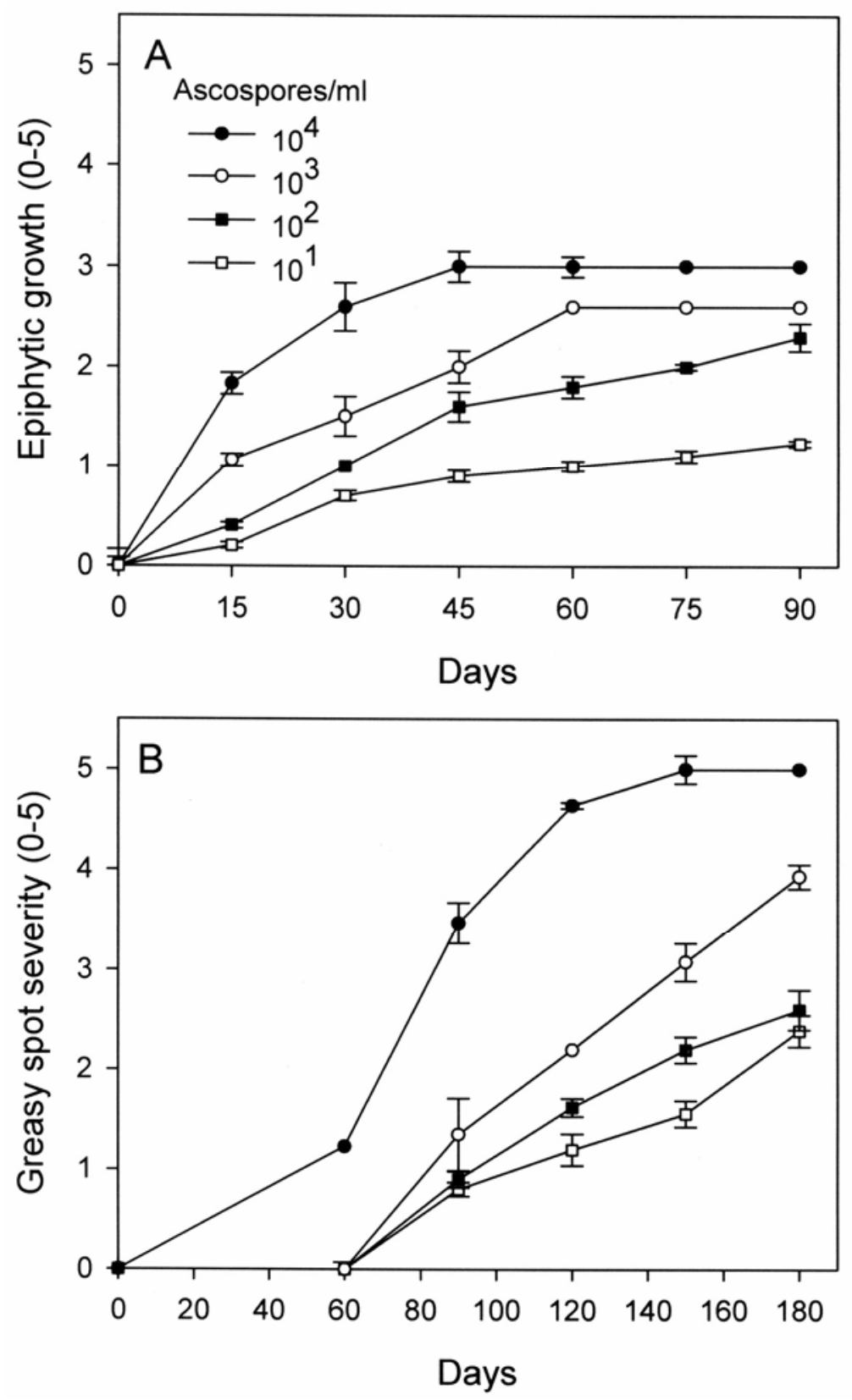

Fig. 1. Effect of ascospore inoculum dose of Mycosphaerella citri on the time course of development of epiphytic growth and the development of greasy spot on rough lemon seedlings. Bars represent the standard error of the mean of three experiments; absence of error bars indicates that the standard error was smaller than the width of the symbol. 
The variable effectiveness of the different fungicides allowed establishment of different levels of control of epiphytic growth and disease severity in each test. In August 2003 and 2004, 10 leaves were collected from previously tagged spring growth flush in each of the two-tree replicate plots in August 2002 and 2003 when epiphytic growth on the leaves was at its maximum (10). Thirty discs $(7 \mathrm{~mm}$ in diameter) were cut arbitrarily from the leaves collected. Leaf discs were processed and the epiphytic growth rated using the procedure described above. Greasy spot severity was rated on the same scale as that used for greenhouse experiments. All leaves on 20 shoots per replicate plot on the spring flush growth tagged in April to May 2002 and 2003 were rated in February to March of the following year. The averages for each fungicide treatment were calculated and regression analysis was used to relate epiphytic growth and disease severity.

Leaf age. Rough lemon seedlings were inoculated under greenhouse conditions to determine the effect of leaf age on symptom severity. Seedlings were cut off near the base and a single new shoot allowed to emerge and grow. The shoot was marked after every 10 days to allow determination of the leaf age following the procedure used by Schwabe (12) for apple scab. When the basal leaves were 60 days old, the shoot tip was removed to stop further growth to avoid confusion between inoculated and noninoculated leaves, and then the plants were inoculated. Three experiments were conducted, two in April and one in June 2003. Seven replicate plants

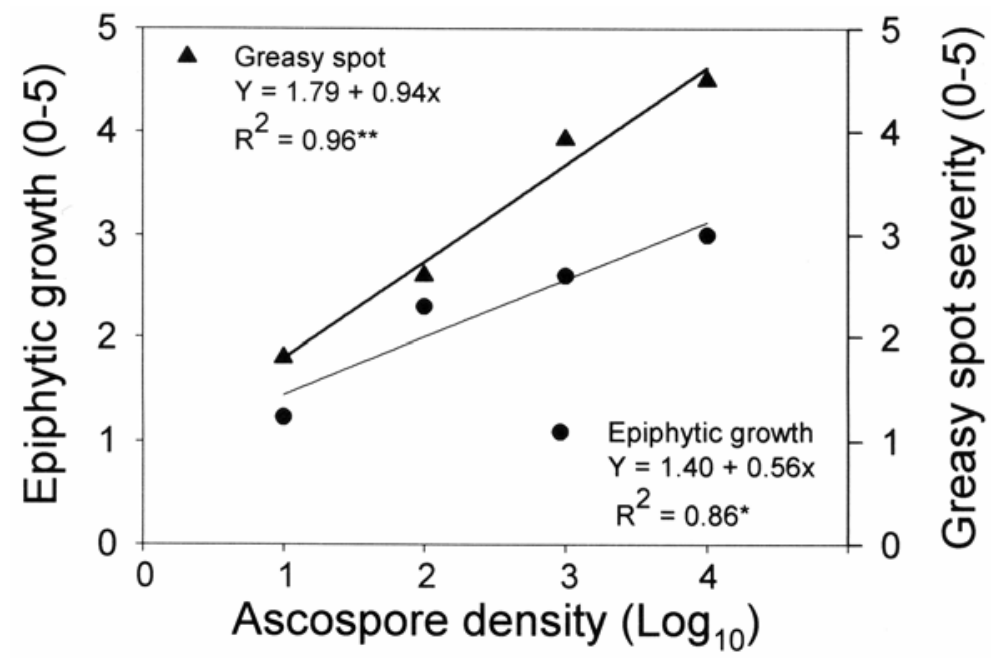

Fig. 2. Effect of ascospore inoculum dose on the epiphytic growth of Mycosphaerella citri after 75 days and the severity of greasy spot on rough lemon seedlings after 150 days.

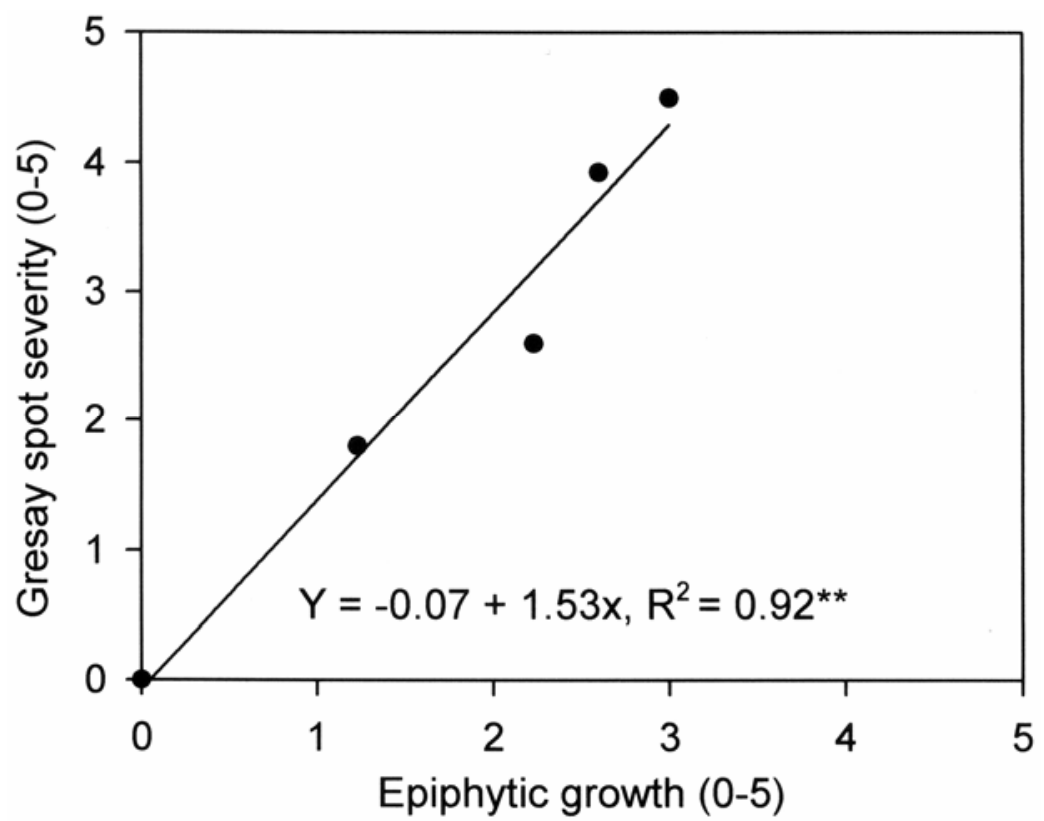

Fig. 3. Relationship between the epiphytic growth of Mycosphaerella citri after 75 days and greasy spot severity after 150 days on rough lemon seedlings inoculated with different doses of ascospores.

were used and greasy spot severity was rated on all leaves after 120 days. There were three to four leaves for rating in each age category on each plant. The effect of leaf age on disease severity was determined by analysis of variance. There was a significant interaction between leaf age and experiment and, thus, the results of each experiment are presented along with the means and standard errors of the means.

Fungicide timing. Two experiments were performed under greenhouse conditions to determine the residual activity of the fungicide prior to inoculation. Groups of six plants were sprayed to run-off with fenbuconazole (Enable 2F) at $0.5 \mathrm{ml} /$ liter at $50,40,30,20$, and 10 days prior to inoculation and other groups of six plants were sprayed at 10,20,30,40, and 50 days postinoculation. One set of six plants was not treated with fungicide as control. Three of the plants in each replicate were used for destructive sampling at 75 days after inoculation and symptom severity was rated on the remaining three after 120 days. The outcome of the two experiments was similar and the means and standard errors of the means were calculated across the two tests.

\section{RESULTS}

Ascospore dose. The epiphytic growth was most rapid on plants inoculated with $10^{4}$ ascospores $/ \mathrm{ml}$ and reached a maximum in 45 days (Fig. 1A). Growth progressed more slowly with lower doses and did not reach the levels attained with $10^{4} / \mathrm{ml}$ even after 90 days. Lesions developed quickly on plants inoculated with $10^{4} / \mathrm{ml}$ and plants were already showing symptoms after 60 days (Fig. 1B). Plants inoculated with lower doses did not show symptoms until 90 days postinoculation. Symptom severity did not reach the same levels with lower doses even after 180 days. There was a significant linear relationship of epiphytic growth and greasy spot severity to the $\log _{10}$ of the ascospore dose (Fig. 2).

Epiphytic growth and disease severity. The data from the greenhouse experiments were used to relate epiphytic growth and disease severity (Fig. 3). Each ascospore dose produced different levels of epiphytic growth. There was a highly significant linear relationship between epiphytic growth and disease severity.

A strong relationship between epiphytic growth and disease severity existed in greenhouse experiments; therefore, we attempted to determine whether such a relationship held in the field. Disease severity as assessed in February to March on spring flush leaves from the previous year was related to epiphytic growth determined in August of the previous year. The relationship was significant in all six field trials (Fig. 4). However, in some cases, the relationship was not strong particularly where disease severity was low (Fig. 4E). 


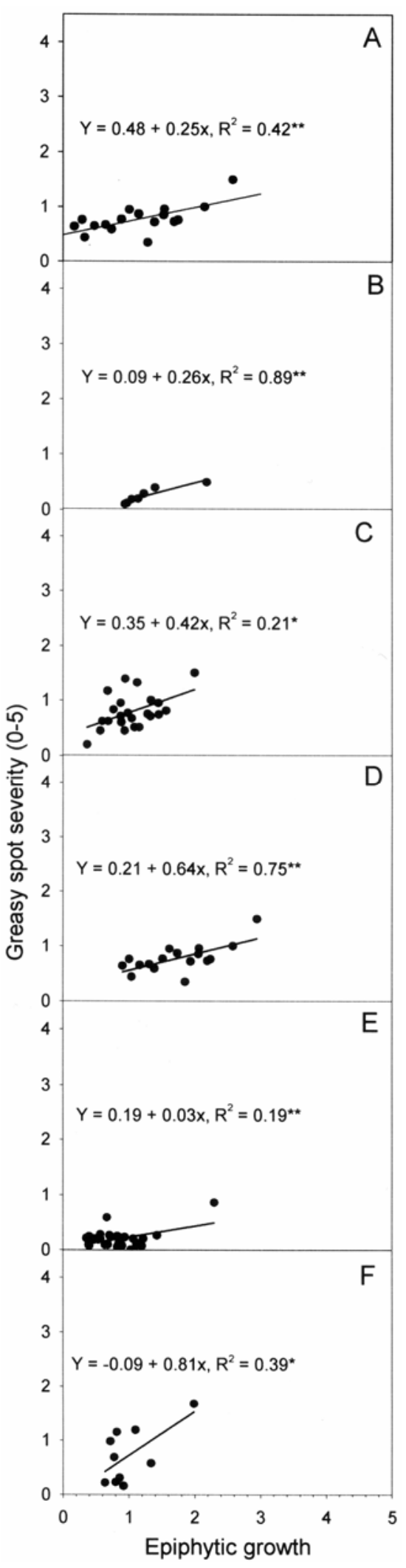

Fig. 4. Relationship of epiphytic growth of Mycosphaerella citri measured in August to final greasy spot severity measured in February to March the following year on grapefruit trees treated with various fungicides and other disease control products. A, Marsh White grapefruit 2002-03, B, Redblush grapefruit, 2002-03, C, Ruby Red grapefruit, 2002-03, D, Ray Ruby grapefruit, 2002-03, E, Marsh White grapefruit 2003-04, and F, Ruby Red grapefruit 2003-04.
The highest values in each case represent the unsprayed control. If that value is removed from the regression, $R^{2}$ values are much lower and, in many cases, not significant.

Leaf age. The age of the leaf was not a significant factor in any of the three experiments conducted when analyzed individually or together (Table 1). Experiment was significant in the analysis $(P \leq 0.01)$ and the experiment-treatment interaction was minimally significant $(P=0.04)$.

Fungicide timing. Applications of fenbuconazole prior to inoculation under greenhouse conditions were highly effective in reducing epiphytic growth and symptom severity (Fig. 5). Even when applied up to 50 days prior to inoculation, fenbuconazole reduced epiphytic growth and greasy spot. When applied up to 30 days prior to inoculation, it completely eliminated disease. Applications after inoculation were much less effective. When applied 10 days after inoculation, fenbuconazole eliminated epiphytic growth and disease development. At 20 and 30 days after inoculation, disease was still reduced, but sprays 40 and 50 days postinoculation were ineffective.

\section{DISCUSSION}

The question of ascospore dose is an important one for interpretation of the relationship of greasy spot severity and changes in cultural practices and potential control measures. The peak of ascospore discharge has moved from the rainy season months of June and July in the 1970s $(18,22)$ to the dry months of April and May in more recent years $(11,16)$. Ascospores are relatively fragile and survive rather short periods of unfavorable conditions (18). Trap plants exposed in the field for short periods in April and early May develop much less greasy spot than those exposed in June and July, even though ascospore numbers are much less in June and July $(11,15,16)$. Summer flush that emerges in July and August when conditions are favorable is severely affected even though inoculum levels are low. Thus, disease development appears to be much more dependent on environmental conditions than on availability of large numbers of ascospores.

Table 1. Effect on leaf age on greasy spot severity after inoculation of rough lemon seedlings with ascospores of Mycosphaerella citri

\begin{tabular}{lcccc}
\hline & \multicolumn{4}{c}{ Greasy spot severity (0-to-5 scale) } \\
\cline { 2 - 5 } Leaf age & Exp. 1 & Exp. 2 & Exp. 3 & Average \\
\hline$>10$ days & 3.06 & 2.83 & 2.82 & $2.90 \pm 0.07$ \\
11-20 days & 3.80 & 3.58 & 2.53 & $3.30 \pm 0.39$ \\
21-30 days & 3.68 & 3.30 & 2.42 & $3.13 \pm 0.37$ \\
31-40 days & 3.03 & 3.45 & 2.46 & $2.98 \pm 0.68$ \\
41-50 days & 2.96 & 3.60 & 3.14 & $3.23 \pm 0.19$ \\
60 days & 3.15 & 2.91 & 2.28 & $2.78 \pm 0.25$ \\
\hline
\end{tabular}

${ }^{a}$ Greasy spot severity was rated using a scale of $0=$ no disease to $5=>20 \%$ of the leaf area covered with lesions.

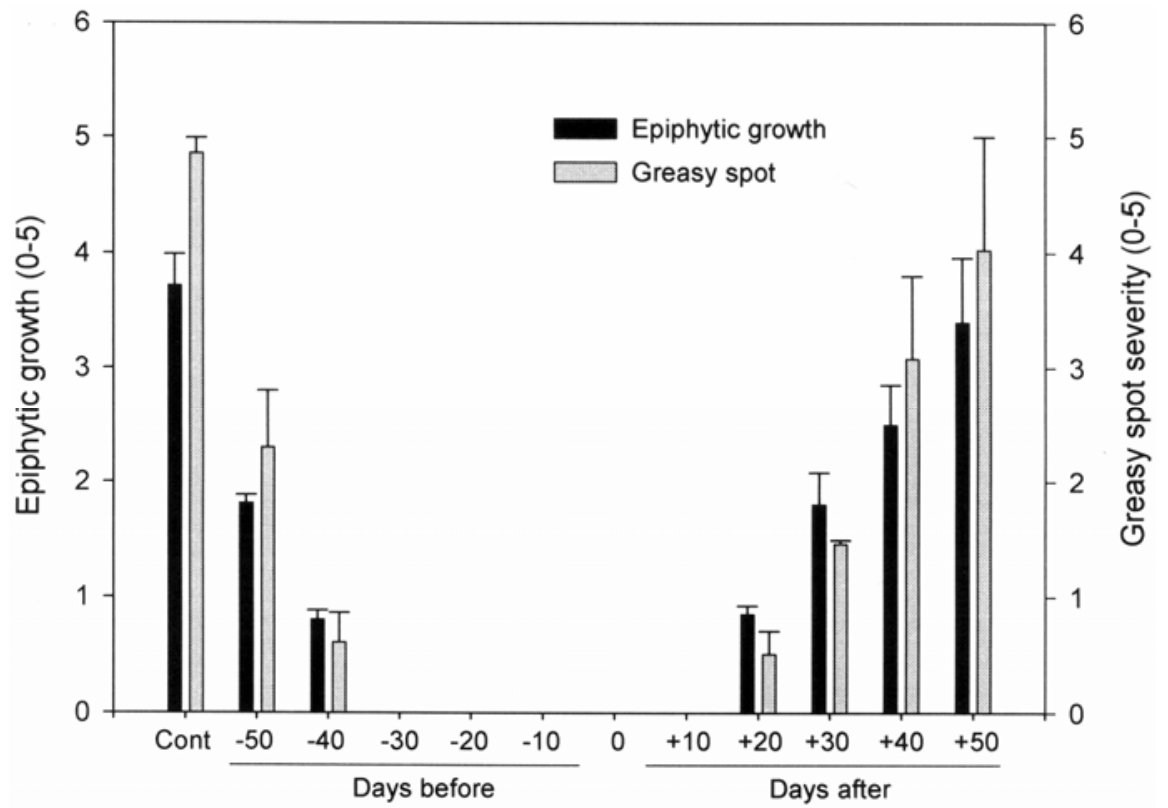

Fig. 5. Effect of time of application of fenbuconazole before and after inoculation with ascospores on the development of epiphytic growth of Mycosphaerella citri after 75 days and on the development of greasy spot symptoms on rough lemon seedlings after 120 days. Bars represent the standard error of the mean of two experiments. 
The change in the peak of ascospore release probably was due to the switch from overhead irrigation that was applied every 2 to 3 weeks to microsprinkler irrigation that normally is applied two to three times per week. Wetting and drying three times per week speeds and maximizes pseudothecia and ascospore production (9). The change in irrigation practices greatly reduced the inoculum availability during the most favorable period, yet did not noticeably reduce greasy spot incidence or severity. However, the change in irrigation practices was accompanied by a switch from tillage to chemical weed control. Tillage may have buried a large amount of inoculum and more weed cover may have interfered with ascospore dispersal. Thus, benefits gained by one change in cultural practices may have been offset by another change.

Greasy spot symptoms develop very slowly and the effects of fungicide treatments applied in June often cannot be evaluated until February or March of the following year. One of the purposes of evaluating epiphytic growth under field conditions was to determine whether it was predictive of fungicide effects on symptom development. Although there was a significant relationship of epiphytic growth in August and symptoms later, these factors were not tightly correlated. Whereas single sampling for epiphytic growth in August may give an indication of whether a treatment is effective, it is not a substitute for symptom evaluation.

The current study indicates that it will require a very large reduction in inoculum to achieve significant disease control. A $90 \%$ reduction from $10^{4}$ to $10^{3}$ ascospore $/ \mathrm{ml}$ reduced disease severity and slowed symptom development, but a $99 \%$ reduction was much better. Thus, it is understandable that no obvious response to the shift in the ascospore peak was observed by growers. We investigated the use of urea and lime applications and extra irrigations to leaf litter to reduce inoculum (10). Under controlled conditions, inoculum reductions of up to $90 \%$ can be achieved. It probably will be more difficult to achieve such reductions under field conditions and the practicality of such measures remains to be seen.

The log-linear relationship of inoculum dose of M. citri and severity of greasy spot is similar to classical interactions of many other host-pathogen combinations (1). However, that relationship was not necessarily expected because low numbers of ascospores could produce a great deal of epiphytic growth and many infections under favorable conditions. Whiteside (21) has demonstrated that honeydew produced by insects greatly increased greasy spot severity. In the current study, a single infection period followed by humid condi- tions on plants free of insects produced the log-linear response. However, under field conditions, that relationship may not hold, especially in the summer when conditions are favorable for infection (11).

Leaf age is not a factor in disease development or in timing of fungicide applications. The spring growth flush emerges in March but infection does not occur until June, when conditions are favorable. These leaves are mature when infected, whereas leaves on shoots that emerge in June and July probably are very immature when infected.

The spray timing tests conducted in this study are artificial in the sense that the plants were never exposed to rainfall. These data, however, give a good idea of the maximum periods that fenbuconazole would be effective before and after inoculation. Preventive applications are effective for up to 50 days. These data are consistent with field trials with this fungicide (9) as well as with copper fungicides $(15,16,23)$. Timing on spring flush leaves is not critical because infection does not occur until June to July. However, applications in April are not nearly as effective as May or June sprays (16).

The effectiveness of sprays applied after inoculation is not nearly as great as anticipated by Whiteside (24), who predicted that sprays of copper fungicides and petroleum oils could be applied up to several weeks later. However, it is consistent with our findings (11) that epiphytic growth develops quickly on summer growth and that those leaves need to be treated soon after emergence. This study supports the view that leaves emerging in the summer when conditions are favorable need to be treated promptly.

\section{ACKNOWLEDGMENTS}

We thank T. Johnston, C. Geanangel, and L. Zhang for excellent technical assistance.

\section{LITERATURE CITED}

1. Horsfall, J. G., and Cowling, E. B. 1978. How disease develops in populations. In: Plant Disease, An Advanced Treatise, Vol. II. Academic Press, New York.

2. Johnston, T., and Timmer, L. W. 2004. Evaluation of products for control of citrus greasy spot on red grapefruit, 2002-03. Fungic. Nematicide Tests 59:V027.DOI.10.1094/FN59. The American Phytopathological Society, St. Paul, MN.

3. Johnston, T., and Timmer, L. W. 2004. Evaluation of products for control of citrus greasy spot on Marsh grapefruit, 2002-03. Fungic. Nematicide Tests 59:V029.DOI.10.1094/FN57. The American Phytopathological Society, St. Paul, MN.

4. Johnston, T., and Timmer, L. W. 2004. Evaluation of products for control of citrus greasy spot on Redblush grapefruit, 2002-03. Fungic. Nematicide Tests 59:V030.DOI.10.1094/FN5. The American Phytopathological Society, St. Paul, MN.

5. Johnson, T., and Timmer, L. W. 2005. Evaluation of products for control of citrus greasy spot on red grapefruit, 2003-04. Fungic.
Nematicide Tests 60:V024.M06.DOI.10.1094/ FN60. The American Phytopathological Society, St. Paul, MN.

6. Johnson, T., and Timmer, L. W. 2005. Evaluation of products for control of citrus greasy spot on Marsh grapefruit, 2003-04. Fungic. Nematicide Tests 60:V025.M06.DOI.10.1094/ FN60. The American Phytopathological Society, St. Paul, MN.

7. Mondal, S. N., Gottwald, T. R., and Timmer, L. W. 2003. Environmental factors affecting the release and dispersal of ascospores of Mycosphaerella citri. Phytopathology 93:1031-1036.

8. Mondal, S. N., Howd, D. S., Brlansky, R. H., and Timmer, L. W. 2004. Mating and pseudothecial development in Mycosphaerella citri, the cause of citrus greasy spot. Phytopathology 94:978-982.

9. Mondal, S. N., and Timmer, L. W. 2002. Environmental factors affecting pseudothecial development and ascospore production of $M y$ cosphaerella citri the cause of citrus greasy spot. Phytopathology 92:1267-1275.

10. Mondal, S. N., and Timmer, L. W. 2003. The effect of urea, $\mathrm{CaCO}_{3}$, and dolomite on pseudothecial development and ascospore production of Mycosphaerella citri. Plant Dis. 86:478-483.

11. Mondal, S. N., and Timmer, L. W. 2003. The relationship of epiphytic growth of $M y$ cosphaerella citri to greasy spot development on citrus and to disease control with fenbuconazole. Plant Dis. 87:186-192.

12. Schwabe, W. F. S. 1979. Changes in scab susceptibility of apple leaves as influenced by age. Phytophylactica 11:53-56.

13. Skaria, M., and Zhang, T. 1996. A leaf disk clearing and staining technique to quantify ascospores of Mycosphaerella citri in young citrus leaves. Subtrop. Plant Sci. 48:16-18.

14. Timmer L. W., and Gottwald, T. R. 2000. Greasy spot and similar diseases. Pages 25-28 in: Compendium of Citrus Diseases. L. W. Timmer, S. M. Garnsey, and J. H. Graham, eds. American Phytopathological Society Press, St. Paul, MN.

15. Timmer, L. W., Gottwald, T. R., McGovern, R. J., and Zitko, S. E. 1995. Time of ascospore release and infection by Mycosphaerella citri in central and southwest Florida. Proc. Fla. State Hortic. Soc. 108:374-377.

16. Timmer, L. W., Roberts, P. D., Darhower, H. M., Bushong, P. M., Stover, E. W., Peever, T. L., and Íbañez, A. M. 2000. Epidemiology and control of citrus greasy spot in different citrus-growing areas in Florida. Plant Dis. 84:1294-1298.

17. Timmer, L. W., Rogers, M. E., and Baker, R. S. 2005. 2005 Florida Citrus Pest Management Guide. Univ. Florida, IFAS, Publ. No. SP-43.

18. Whiteside, J. O. 1970. Etiology and epidemiology of citrus greasy spot. Phytopathology 60:1409-1414.

19. Whiteside, J. O. 1972. Histopathology of citrus greasy spot and identification of the causal fungus. Phytopathology 62:260-263.

20. Whiteside, J. O. 1973. The possibilities of using ground sprays to control citrus greasy spot. Proc. Fla. State Hortic. Soc. 86:19-23.

21. Whiteside, J. O. 1974. Environmental factors affecting infection of citrus leaves by $M y$ cosphaerella citri. Phytopathology 64:115-120.

22. Whiteside, J. O. 1977. Behavior and control of greasy spot in Florida citrus groves. Proc. Intl. Soc. Citricult. 3:981-986.

23. Whiteside, J. O. 1982. Timing of single-spray treatments for optimal control of greasy spot on grapefruit leaves and fruit. Plant Dis. 66:687-690.

24. Whiteside, J. O. 1983. Viewpoint on the spraying of citrus trees for greasy spot control. Citrus Ind. 64(5):4, 6, 7, 9-11. 